Эпидемиология алкоголизма и алкогольных психозов в

\title{
Республике Мордовия
}

\section{Костылёв Д.А. ${ }^{1}$, Подсеваткин В.Г. ${ }^{1}$, Кирюхина С.В. ${ }^{1}$}

\author{
${ }^{1}$ НИ МГУ им. Н.П.Огарёва, медицинский институт, кафедра нервных болезней \\ и психиатрии. 430032 РМ, г.Саранск, ул.Ульянова, д.26А
}

\begin{abstract}
Аннотация.
Цель исследования. Основной целью исследования являлась оценка эпидемиологии алкоголизма и алкогольных психозов коренного населения Республики Мордовия. Материалы и методы: данные статистической отчетности по Республике Мордовия, Российской Федерации, сравнение коренного населения с остальными жителями республики. В рамках исследования применялись клинико-эпидемиологический и статистический методы. Результаты. Болезненность алкоголизмом и алкогольными психозами находится на достаточно высоком уровне и в динамике за 5 лет не приблизилась к показателю по РФ, поэтому профилактика алкогольной зависимости должна являться одной из важнейших задач для этой административной территории. Первичная заболеваемость алкоголизмом и алкогольными психозами также превышает уровень по РФ. При чём, где в основном проживает коренное население эта разница достигает в 2-4 раза.Возможными причинами данной ситуации является то, что основная доля коренного населения проживает на селе, а там развито самогоноварение и трудно устроиться на работу. Также этому может способствовать генетическая предрасположенность в виде мутаций ферментов алкогольдегидрогеназы и ацетальдегиддегидрогеназы, при которой опьянение наступает позже, а похмельный синдром практически отсутствует.
\end{abstract}

Ключевые слова: эпидемиология, алкоголизм, алкогольные психозы, Республика Мордовия.

УДК 616.89-02-054

\section{Epidemiology of alcoholism and alcohol psychosis in the Republic}

\section{of Mordovia}

\author{
Kostylev, D. A. ${ }^{1}$, Podsevatkin V. G. ${ }^{1}$, Kiryukhina S. V. ${ }^{1}$
}

${ }^{1}$ Ogarev Mordovia State University Medical Institute. Republic of Mordovia, Saransk, Ulyanov str., 26A

Abstract.

Research objective. The main purpose of the study was to assess the epidemiology of alcoholism and alcoholic psychosis of the indigenous population of the Republic of Mordovia. Materials and methods: data of statistical reporting on the Republic of Mordovia, the Russian Federation, comparison of the indigenous population with other inhabitants of the Republic. The study used clinical, epidemiological and statistical methods. Results. The morbidity of alcoholism and alcoholic psychoses is at a high level and in the dynamics for 5 years is not close to the indicator for the Russian Federation, so the prevention of alcohol dependence should be one of the most important tasks for this administrative territory. The primary incidence of alcoholism and alcoholic psychosis also exceeds the level in Russia. At the same time, where the indigenous population mainly lives, this difference reaches 2-4 times.Possible reasons for this situation are that the majority of the indigenous population lives in rural areas, where moonshine is developed and it is difficult to get a job. Also, this can be facilitated by genetic predisposition in the form of mutations of enzymes of alcohol dehydrogenase and acetaldehyde dehydrogenase, in which intoxication occurs later, and hangover syndrome is practically absent.

Keywords: epidemiology, alcoholism, alcoholic psychoses, Republic of Mordovia 
Введение. Алкоголизм в наше время представляет собой чрезвычайно важное заболевание как для нашего государства, так и для мира в целом. Это объясняется тем, что злоупотребление алкоголя связано с огромными медико-социальными, экономическими и демографическими потерями. И поэтому решение задачи по снижению алкогольной зависимости должно быть приоритетным направлением развития, так как это одна из угроз национальной безопасности в сфере здравоохранения и здоровья нации[7].

Население РФ включает в себя огромное количество национальностей и в некоторых регионах, где преимущественно проживает коренное население, наблюдаются высокие показатели заболеваемости алкоголизмом и алкогольными психозами. А именно это выражено в зоне проживания финно-угорских народов (Республика Марий Эл, Республика Удмуртия, Республика Коми, Республика Мордовия), где они превышают средний уровень заболеваемости по стране в целом[2].

В силу данной особенности, некоторые ученые провели исследования, на основе которых сформулировали, что у больных финно-угров быстрее формируется алкогольная зависимость, характеризующаяся тяжелым течением, сопровождающееся частым возникновением неотложных состояний[5,6,8].

В Республике Мордовия подобных исследований не проводилось, а так как здесь в большинстве своём проживает финно-угорское население (мордва) [4], то оно здесь просто необходимо, во-первых потому, что показатель заболеваемости здесь один из наиболее высоких по стране [2], а во-вторых как уже сказано выше алкогольная зависимость у финноугорских народов формируется быстро и протекает с тяжелыми последствиями.

Возможно, быстрое возникновение алкогольной зависимости связано с тем, что у финно-угорских народов существует генетическая предрасположенность в виде мутации аллелей, отвечающих за кодирование ферментов алкогольдегидрогеназы и ацетальдегиддегидрогеназы, при взаимодействии которых медленнее наступает опьянение, а похмельный синдром практически отсутствует из-за быстрого расщепления ацетальдегида[1]. В связи с этим необходимо углубленное медико-генетическое исследование для выяснения истинных причин заболевания. И в мире подобные исследования уже проводились, что помогло определить генетические предпосылки алкоголизма у некоторых народов[9].

Всё это приводит к тому, что купирование неотложных состояний и дальнейшая реабилитация больных требует больших финансовых затрат; много преступлений совершается в состоянии алкогольного опьянения, для контроля этого необходимо напряжение правоохранительных служб. 
Поэтому очень важно выявить такого больного на ранней стадии заболевания, оказать комплексное лечение, провести полноценную реабилитацию и разработать меры профилактики, конкретные для данного региона.

Таким образом, научная неразработанность и медико-социальная значимость изучения алкоголизма и алкогольных психозов среди финно-угорского населения, а именно в Республике Мордовия, определяют актуальность проблемы.

Цель исследования. Основной целью исследования являлась оценка эпидемиологии алкоголизма и алкогольных психозов коренного населения Республики Мордовия.

\section{Задачи.}

1. Определить национальный состав Республики Мордовия.

2. Изучить распространенность (болезненность и заболеваемость) алкоголизмом и алкогольными психозами в Республике Мордовия.

3. Выявить причины способствующие формированию алкогольной зависимости у населения.

Материалы и методы: данные статистической отчетности по Республике Мордовия, Российской Федерации, сравнение коренного населения с остальными жителями республики. В рамках исследования применялись клинико-эпидемиологический и статистический методы.

Научная новизна. Проведен сравнительный анализ распространенности алкоголизма и алкогольных психозов в Республике Мордовия и по Российской Федерации в целом. Выявлены предпосылки для формирования алкогольной зависимости.

Практическая значимость. Знание основных закономерностей распространенности алкоголизма и алкогольных психозов в Республике Мордовия позволит правильно оценить наркологическую ситуацию в регионе и продумать пути её улучшения. Знание этнокультуральных особенностей больных алкогольными психозами даст возможность повысить эффективность профилактических мероприятий в финно-угорской и славянской субпопуляциях населения республики.

Результаты. Для того, чтобы оценить эпидемиологию алкогольной зависимости в Республике Мордовия необходимо знать, какой процент коренного населения проживает на данной территории. К концу 2010 г. общая численность населения республики составляла 834755 человек, коренное населения - 333112 человек, из них 153229 мужчин и 179883 женщин. В процентном соотношении это выглядит так: мордовское население составляет $40 \%$, русские - 53\%, татары - 5\%, другие национальности - $2 \%$ (рис. 1 ). 


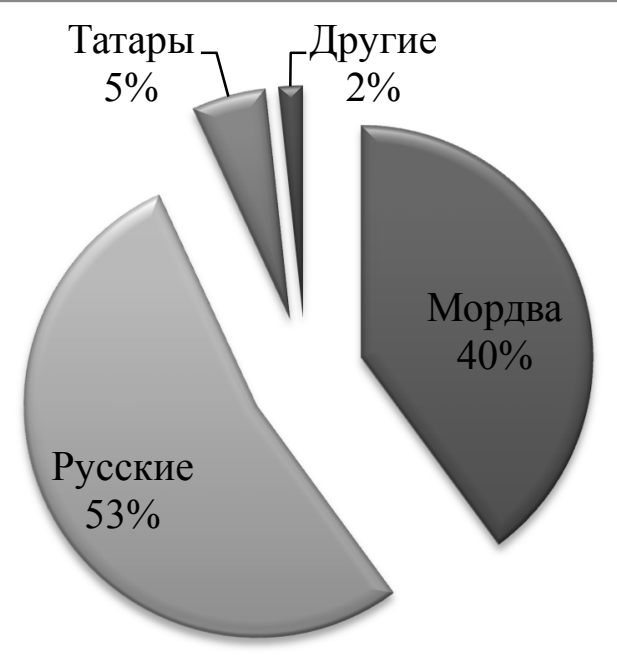

\section{Рисунок 1 - Состав населения Республики Мордовия}

Анализируя динамику болезненности в Республике Мордовия по сравнению с данными по стране за период с 2011 по 2016 год видно, что происходит постепенное снижение уровня болезненности алкоголизмом и алкогольными психозами с 1460 до 1237,8 (на 15,2\%), но следует отметить, что оно происходит неравномерно, то резким снижением с 1396,3 до 1254,3, то очень медленными темпами с 1254,3 до 1237,8. И особенно неблагоприятно характеризует этот наркологический показатель то, что он так и не приблизился к общероссийскому (рис.1).

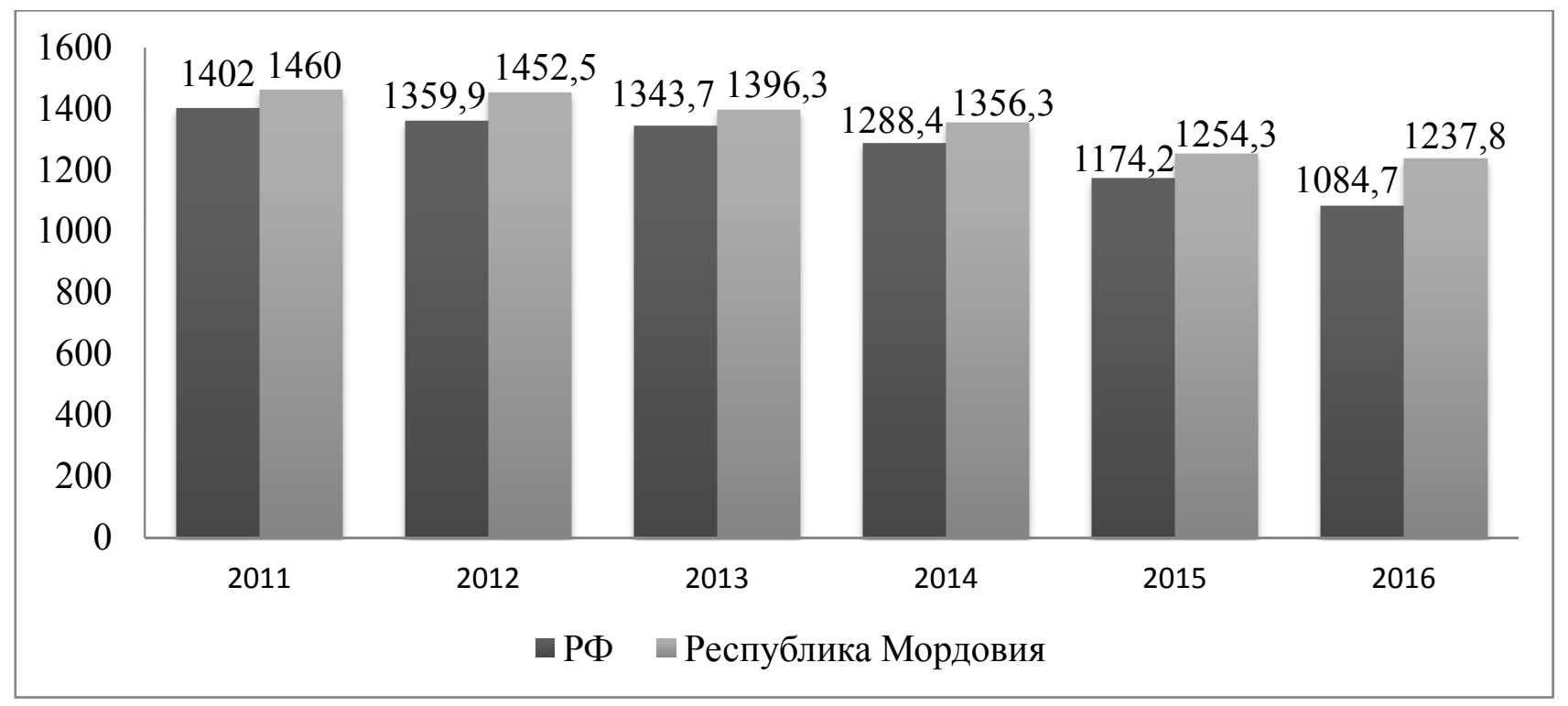

Рисунок 2 - Болезненность алкоголизмом и алкогольными психозами в РФ и РМ за 2011-2016 гг. (на 100000 населения)

Как известно, частота возникновения осложнений алкогольной зависимости характеризует тяжесть его течения. На представленном графике мы наблюдаем пилообразную картину динамики распространенности алкогольных психозов в РМ, когда 
происходит то снижение уровня болезненности $(40,1)$, то повышается почти до исходного уровня $(45,9)$. Это отрицательно влияет на течение алкоголизма у населения РМ (рис.3).

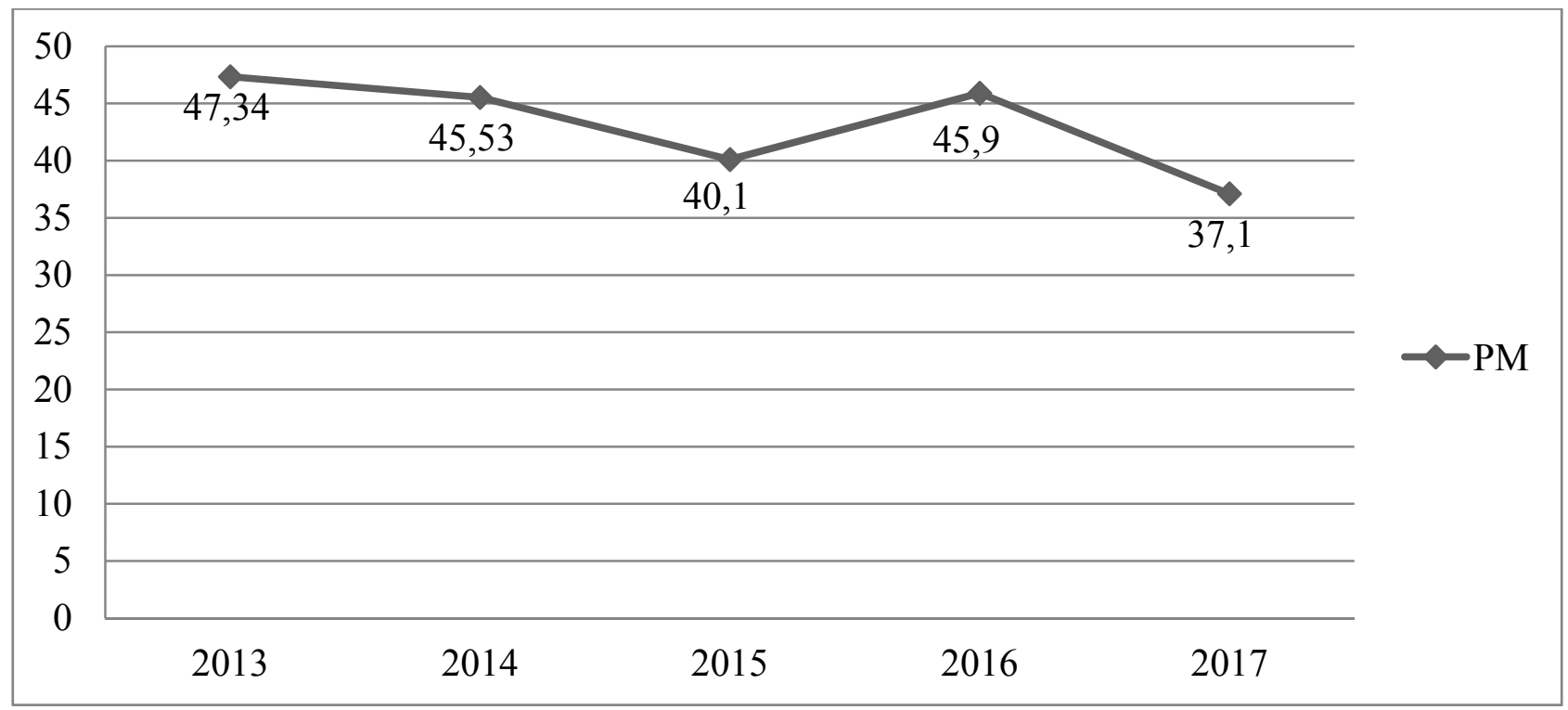

Рисунок 3 - Динамика распространенности алкогольных психозов в РМ за 2013-2017 гг. (на 100000 населения)

В дополнение к вышесказанному, необходимо подчеркнуть, что и первичная заболеваемость населения Республики Мордовия, выше чем средняя по стране. Это подтверждает, что алкогольная зависимость формируется чаще и быстрее. Хотя и она тоже снизилась за последнее время со 131,4 до 78,6. (рис.2).

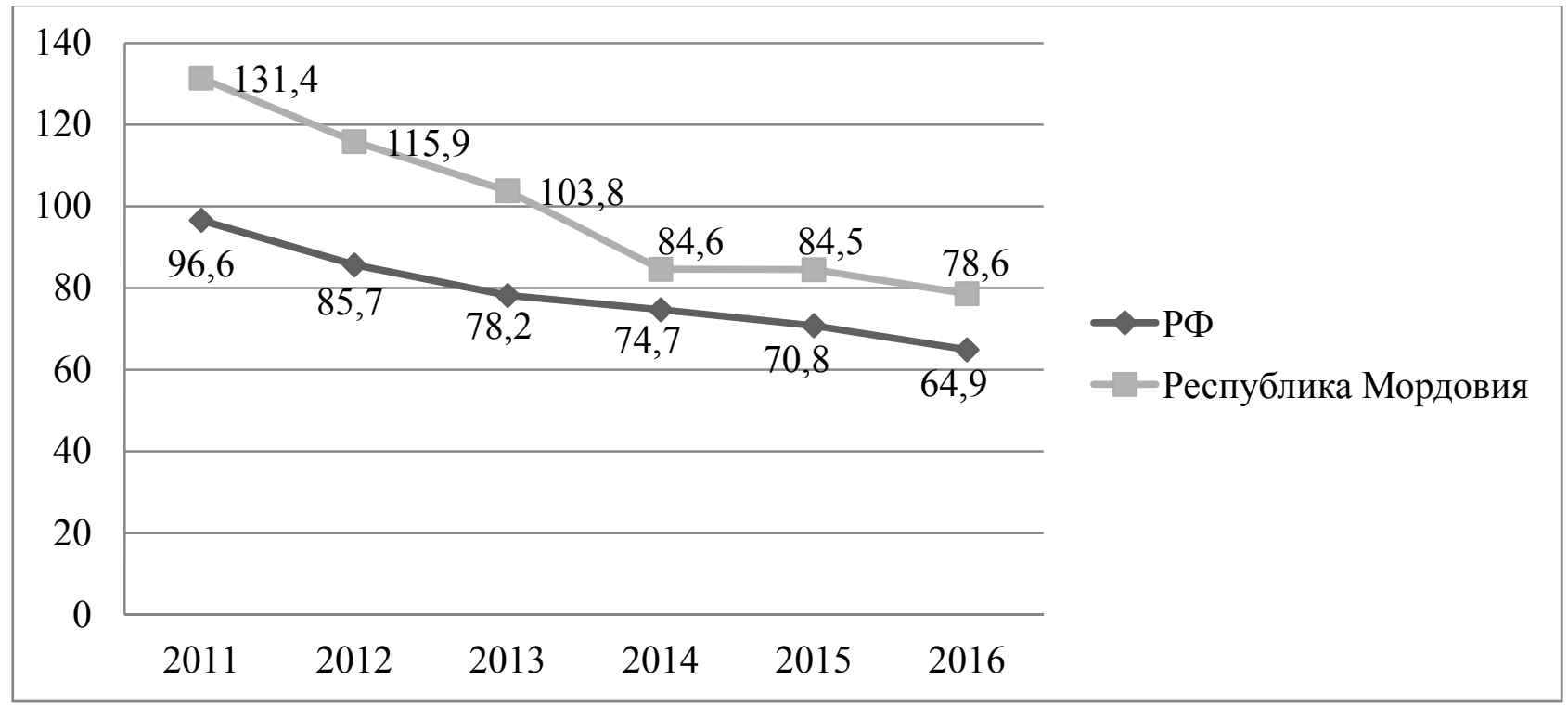

Рисунок 4 - Динамика первичной заболеваемости алкоголизмом и алкогольными психозами в РФ и РМ (на 100000 населения)

Наглядно демонстрирует повышенную заболеваемость алкоголизмом в Мордовии, процентный состав мордовского населения в районах республики. Там где проживает более 
30\% коренного населения отмечается рост показателей за 2016 и 2017 годы. Возможными причинами этого явления могло послужить то, что данные регионы находятся далеко от центра, а там сложнее найти работу, больше свободного времени и сильнее развито самогоноварение.

Таблица 1.

\section{Наиболее высокая заболеваемость алкоголизмом и алкогольными психозами в районах} PM

\begin{tabular}{|c|c|c|c|c|}
\hline \multirow{2}{*}{$\begin{array}{c}\text { № } \\
\text { п/п }\end{array}$} & Районы РМ & $\begin{array}{c}\text { Процентный состав } \\
\text { мордвы }\end{array}$ & \multicolumn{2}{|c|}{$\begin{array}{c}\text { Заболеваемость алкоголизмом и АП } \\
\text { на } 100 \text { тыс. населения }\end{array}$} \\
\cline { 3 - 5 } & & 2016 г & 2017 г \\
\hline 1. & Атюрьевский & $90,3 \%$ & 115,3 & 132,0 \\
\hline 2. & Б.Березниковский & $56,8 \%$ & 85,7 & 182,0 \\
\hline 3. & Ельниковский & $43,9 \%$ & 126,6 & 279,2 \\
\hline 4. & Инсарский & $35,6 \%$ & 46,7 & 112,1 \\
\hline 5. & Ичалковский & $48,6 \%$ & 47,9 & 102,4 \\
\hline 6. & Рузаевский & $30,9 \%$ & 99,0 & 141,2 \\
\hline
\end{tabular}

Немаловажным является тот факт, что употребление алкоголя у мордвы являлось частью их ритуальной жизни, когда для празднования готовился слабоалкогольный продукт - поза, которым затем осуществлялось коллективное угощение. Особенно это было характерно для сельской местности[3].

Заключение. Национальный состав Республики Мордовия включает в себя три основные группы: мордва, русские, татары. Мордовский этнос составляет чуть более трети от всего проживающего на данной территории населения.

Болезненность алкоголизмом и алкогольными психозами находится на достаточно высоком уровне и в динамике за 5 лет не приблизилась к показателю по РФ, поэтому профилактика алкогольной зависимости должна являться одной из важнейших задач для этой административной территории.

Это подтверждается и тем, что и первичная заболеваемость алкоголизмом и алкогольными психозами превышает уровень по РФ. При чём, где в основном проживает мордовское население эта разница достигает 2-4x кратного показателя.

Возможными причинами данной ситуации является то, что основная доля коренного населения проживает на селе, а там развито самогоноварение и трудно устроиться на работу. Также этому может способствовать генетическая предрасположенность в виде мутации аллелей отвечающих за ферменты алкогольдегидрогеназу и ацетальдегиддегидрогеназу, при которой опьянение наступает позже, а похмельный синдром практически отсутствует. 
Ещё одним важным аспектом является частое возникновение осложнений алкогольной зависимости - алкогольных психозов. Что неблагоприятно характеризует течение заболевания.

В целом наркологическая обстановка в Республике Мордовия не может считаться благоприятной. Для её улучшения необходимы продумать меры профилактики и улучшить выявление больных на ранней стадии заболевания. 


\section{Список литературы}

1. Алкогольдегидрогеназа 1B (ADH1B). Выявление мутации A143G (Arg47His) [Электронный ресурс] // Лабораторная служба Хеликс URL: https://helix.ru/kb/item/1242 (дата обращения 20.12.2018).

2. Киржанова В.В., Григорова Н.И., Киржанов В.Н., Сидорюк О.В. Основные показатели деятельности наркологической службы в Российской Федерации в 2015-2016 годах.

3. Мордва: Историко-культурные очерки / Ред. кол.: В. А. Балашов (отв. ред.), В. С. Брыжинский, И. А. Ефимов; Рук. авт. коллектива академик Н. П. Макаркин. - Саранск: Мордов. кн. изд-во, 1995. - С. 199-200. - 624 с.

4. Национальный состав населения Республики Мордовия, владение языками и гражданство (по итогам Всероссийской переписи населения 2010 года). Стат. сборник / Мордовиястат C., $2013-99$ c.

5. Новиков А.П., Рахмазова Л.Д., Гильбурд О.А. Эпидемиология алкогольной зависимости в Ханты-Мансийском автономном округе - Югре. Сибирский вестник психиатрии и наркологии. 2017; 4 (97): 38-43.

6. Пантелеев В.Г. Этнокультуральные особенности распространенности, клиники и профилактики алкогольных психозов в Республике Коми Дис. ... докт. мед, наук. М., 2004.

7. Стратегия национальной безопасности РФ до 2020 г. Указ Президента РФ от 12 мая 2009 г. №537

8. Уваров И.А. Особенности клиники и течения алкогольных психозов в Удмуртской Республике. // Наркология. - 2007. - N 10. - с. 47-50.

9. T. Muramatsu, Z. C. Wang, Y. R. Fang, K. B. Hu, H. Yan, K. Yamada, S. Higuchi, S. Harada \& H. Kono (August 1995). "Alcohol and aldehyde dehydrogenase genotypes and drinking behavior of Chinese living in Shanghai”. Human Genetics. 96 (2): 151-154. 